\title{
Sleep Duration and Injury-Related Risk Behaviors Among High School Students — United States, 2007-2013
}

\author{
Anne G. Wheaton, $\mathrm{PhD}^{1}$; Emily O’Malley Olsen, $\mathrm{MSPH}^{2}$; Gabrielle F. Miller, $\mathrm{PhD}^{1}$; Janet B. Croft, $\mathrm{PhD}^{1}$
}

Insufficient sleep is common among high school students and has been associated with an increased risk for motor vehicle crashes (1), sports injuries (2), and occupational injuries (3). To evaluate the association between self-reported sleep duration on an average school night and several injury-related risk behaviors (infrequent bicycle helmet use, infrequent seatbelt use, riding with a driver who had been drinking, drinking and driving, and texting while driving) among U.S. high school students, CDC analyzed data from 50,370 high school students (grades 9-12) who participated in the national Youth Risk Behavior Surveys (YRBSs) in 2007, 2009, 2011, or 2013. The likelihood of each of the five risk behaviors was significantly higher for students who reported sleeping $\leq 7$ hours on an average school night; infrequent seatbelt use, riding with a drinking driver, and drinking and driving were also more likely for students who reported sleeping $\geq 10$ hours compared with 9 hours on an average school night. Although insufficient sleep directly contributes to injury risk, some of the increased risk associated with insufficient sleep might be caused by engaging in injury-related risk behaviors. Intervention efforts aimed at these behaviors might help reduce injuries resulting from sleepiness, as well as provide opportunities for increasing awareness of the importance of sleep.

The national YRBS monitors health-risk behaviors among students in public and private high schools and is conducted by CDC in the spring of odd-numbered years. Each national YRBS uses an independent, three-stage cluster sample design to obtain a nationally representative sample of students in grades $9-12$. The overall response rates* were $68 \%$ in 2007 , $71 \%$ in $2009,71 \%$ in 2011 , and $68 \%$ in 2013 , and sample sizes ranged from 13,583 (2013) to 16,410 (2009). ${ }^{\dagger}$ Students

\footnotetext{
${ }^{*}$ Overall response rate $=($ number of participating schools/number of eligible sampled schools) $\times$ (number of usable questionnaires/number of eligible students sampled). ${ }^{\dagger}$ Data users manuals (http://www.cdc.gov/healthyyouth/yrbs/data/index.htm).
}

completed the anonymous, self-administered questionnaires during a single class period.

The combined analytic sample was composed of 50,370 high school students who responded to questions about sleep duration on an average school night ( $\leq 4$ hours, 5 hours, 6 hours, 7 hours, 8 hours, 9 hours, $\geq 10$ hours); demographic characteristics (sex, grade, and race/ethnicity); and how frequently they used a bicycle helmet (among students who had ridden a bicycle during the past 12 months; responses = never or rarely versus sometimes, most of the time, or always); wore a seatbelt when riding in a car driven by someone else (never or rarely versus sometimes, most of the time, or always); rode in a car or other vehicle with a driver who had been drinking alcohol (i.e., rode with a drinking driver; at least one time during the

\section{INSIDE}

342 Varying Estimates of Sepsis Mortality Using Death Certificates and Administrative Codes United States, 1999-2014

346 Surveillance Systems to Track Progress Toward Polio Eradication - Worldwide, 2014-2015

352 Vital Signs: Preparing for Local Mosquito-Borne Transmission of Zika Virus — United States, 2016

353 Notes from the Field:Thyrotoxicosis After Consumption of Dietary Supplements Purchased Through the Internet — Staten Island, New York, 2015

355 Notes from the Field: Mycobacterium abscessus Infections Among Patients of a Pediatric Dentistry Practice - Georgia, 2015

357 QuickStats

Continuing Education examination available at http://www.cdc.gov/mmwr/cme/conted_info.html\#weekly.

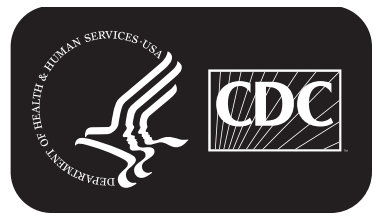

U.S. Department of Health and Human Services Centers for Disease Control and Prevention 
past 30 days versus 0 times); drove a car or other vehicle when they had been drinking alcohol ${ }^{\S}$ (i.e., drinking and driving; at least one time during the past 30 days versus 0 times); or texted or e-mailed while driving a car or other vehicle (i.e., texting while driving; at least 1 day during the past 30 days versus 0 days). The percentage reporting insufficient sleep duration ( $\leq 7$ hours according to the Healthy People 2020 sleep objective for adolescents**) and distribution of hours of sleep were calculated by survey year, sex, grade, and race/ethnicity; pairwise t-tests and ANOVA (i.e., linear trend) were used to assess crude significant differences.

Because no differences were found in mean sleep duration or prevalence of insufficient sleep duration by survey year, data from all four survey years were aggregated for subsequent analyses. Aggregating the data from four survey years provided adequate sample size for the calculation of low prevalence risk behaviors among students reporting each category of sleep duration. Unadjusted prevalence of each risk behavior was

\footnotetext{
${ }^{\S}$ In the 2013 survey, for the first time, the response options for this question included "I did not drive a car or other vehicle during the past 30 days." For compatibility with the results for the drinking and driving question in the 2007, 2009, and 2011 surveys, students who responded "I did not drive" on the 2013 survey were counted as 0 times and included in the denominators.

9 This question was asked for the first time in the 2011 survey. In the 2013 survey, the response options for this question included "I did not drive a car or other vehicle during the past 30 days." For compatibility with the results for the texting or e-mailing and driving question in the 2011 survey, students who responded "I did not drive" on the 2013 survey were counted as 0 days and included in the denominators.

** https://www.healthypeople.gov/2020/topics-objectives/topic/sleep-health.
}

calculated by sleep duration. Pairwise t-tests were used to assess significant differences compared with 9 hours, the median of the sleep duration recommendation for teens by the National Sleep Foundation (4). Logistic regression analyses were used to calculate adjusted prevalence ratios (APRs) and 95\% confidence intervals (CIs) for the likelihood of each injuryrelated behavior with a referent sleep duration of 9 hours and were adjusted for sex, grade, and race/ethnicity. All analyses accounted for the sampling weights and complex survey design. P-values of $<0.05$ were defined to be statistically significant.

Reported sleep duration during an average school night was $\leq 4$ hours for $6.3 \%$ of respondents, 5 hours $(10.5 \%)$, 6 hours (21.9\%), 7 hours (30.1\%), 8 hours $(23.5 \%)$, 9 hours $(5.8 \%)$, and $\geq 10$ hours (1.8\%). Sleep duration varied by sex, grade, and race/ethnicity (Table 1$)$. Female students reported a higher prevalence of insufficient sleep ( $\leq 7$ hours) than did male students $(71.3 \%$ versus $66.4 \%, \mathrm{p}<0.001)$. The percentage reporting insufficient sleep ranged from $59.7 \%$ of students in 9th grade to $76.6 \%$ of students in 12 th grade $(\mathrm{p}<0.001$ for linear trend). Among racial/ethnic groups, the prevalence of insufficient sleep was lowest for American Indian/Alaska Native students (60.3\%) and highest for Asian students (75.7\%).

Overall, $86.1 \%$ of students reported infrequent bicycle helmet use and $8.7 \%$ reported infrequent seatbelt use. Twentysix percent of students reported riding with a drinking driver at least one time during the past 30 days; $8.9 \%$ of students reported drinking and driving; and $30.3 \%$ reported texting while driving during the past 30 days. Unadjusted prevalence

The MMWR series of publications is published by the Center for Surveillance, Epidemiology, and Laboratory Services, Centers for Disease Control and Prevention (CDC), U.S. Department of Health and Human Services, Atlanta, GA 30329-4027.

Suggested citation: [Author names; first three, then et al., if more than six.] [Report title]. MMWR Morb Mortal Wkly Rep 2016;65:[inclusive page numbers].

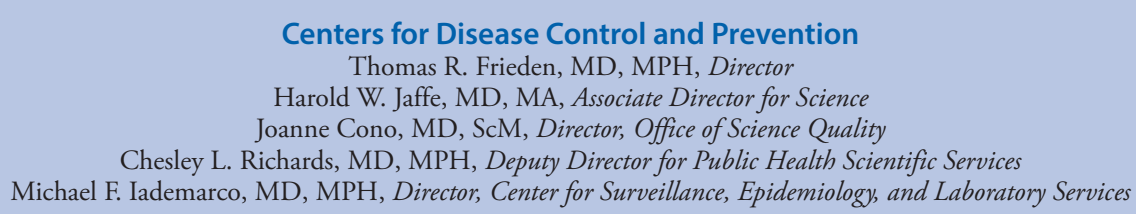

MMWR Editorial and Production Staff (Weekly)

Sonja A. Rasmussen, MD, MS, Editor-in-Chief

Charlotte K. Kent, PhD, MPH, Executive Editor Jacqueline Gindler, MD, Editor

Teresa F. Rutledge, Managing Editor

Douglas W. Weatherwax, Lead Technical Writer-Editor

Soumya Dunworth, PhD, Teresa M. Hood, MS, Technical Writer-Editors

Timothy F. Jones, MD, Chairman

Matthew L. Boulton, MD, MPH

Virginia A. Caine, MD

Katherine Lyon Daniel, $\mathrm{PhD}$

Jonathan E. Fielding, MD, MPH, MBA

David W. Fleming, MD
Martha F. Boyd, Lead Visual Information Specialist

Maureen A. Leahy, Julia C. Martinroe,

Stephen R. Spriggs, Moua Yang, Tong Yang, Visual Information Specialists

Quang M. Doan, MBA, Phyllis H. King, Terraye M. Starr, Information Technology Specialists

MMWR Editorial Board

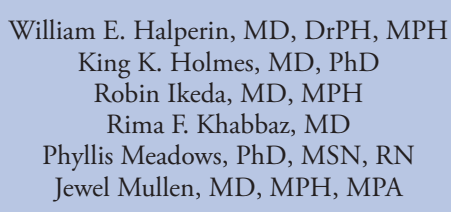

Jeff Niederdeppe, $\mathrm{PhD}$

Patricia Quinlisk, MD, MPH

Patrick L. Remington, MD, MPH Carlos Roig, MS, MA

William L. Roper, MD, MPH

William Schaffner, MD 
Morbidity and Mortality Weekly Report

TABLE 1. Duration of sleep on an average school night, by selected characteristics-Youth Risk Behavior Surveys, United States, 2007, 2009, 2011, and 2013.

\begin{tabular}{|c|c|c|c|c|c|c|c|c|c|}
\hline \multirow[b]{2}{*}{ Characteristic } & \multirow[b]{2}{*}{ No. ${ }^{\dagger}$} & \multicolumn{8}{|c|}{ Sleep duration $\% *(95 \% \mathrm{Cl})$} \\
\hline & & $\begin{array}{c}\leq 7 \mathrm{hrs} \\
\text { (insufficient sleep) }\end{array}$ & $\leq 4 \mathrm{hrs}$ & $5 \mathrm{hrs}$ & $6 \mathrm{hrs}$ & $7 \mathrm{hrs}$ & $8 \mathrm{hrs}$ & $9 \mathrm{hrs}$ & $\geq 10 \mathrm{hrs}$ \\
\hline Total & 50,370 & $68.8(68.0-69.6)$ & $6.3(5.9-6.7)$ & $10.5(10.1-11.0)$ & $21.9(21.3-22.4)$ & $30.1(29.5-30.7)$ & $23.5(22.9-24.2)$ & $5.8(5.5-6.2)$ & $1.8(1.7-2.0)$ \\
\hline \multicolumn{10}{|l|}{ Survey year } \\
\hline 2007 & 11,939 & $69.0(67.0-70.9)$ & $5.8(5.3-6.5)$ & $10.0(9.2-10.9)$ & $22.8(21.6-24.1)$ & $30.4(29.4-31.3)$ & $23.5(21.9-25.3)$ & $5.8(5.2-6.5)$ & $1.6(1.3-2.1)$ \\
\hline 2009 & 14,477 & $69.1(67.5-70.6)$ & $5.5(4.9-6.1)$ & $10.1(9.0-11.4)$ & $21.9(20.9-23.0)$ & $31.6(30.4-32.9)$ & $23.4(22.2-24.5)$ & $5.8(5.3-6.4)$ & $1.7(1.5-2.1)$ \\
\hline 2011 & 11,904 & $68.6(67.2-69.9)$ & $6.6(6.0-7.2)$ & $10.8(10.0-11.6)$ & $21.7(20.6-22.7)$ & $29.6(28.4-30.9)$ & $24.0(22.9-25.1)$ & $5.7(5.1-6.4)$ & $1.7(1.4-2.0)$ \\
\hline 2013 & 12,050 & $68.4(66.9-69.9)$ & $7.4(6.6-8.3)$ & $11.3(10.5-12.2)$ & $21.2(20.2-22.2)$ & $28.5(27.5-29.5)$ & $23.2(22.2-24.2)$ & $6.0(5.3-6.8)$ & $2.4(2.0-2.8)$ \\
\hline \multicolumn{10}{|l|}{ Sex } \\
\hline Female & 25,327 & $71.3(70.4-72.1)$ & $6.3(5.9-6.8)$ & $12.1(11.5-12.8)$ & $23.8(23.0-24.6)$ & $29.0(28.3-29.8)$ & $22.0(21.3-22.8)$ & $5.1(4.7-5.5)$ & $1.6(1.4-1.8)$ \\
\hline Male & 25,043 & $66.4(65.4-67.4)$ & $6.3(5.8-6.7)$ & $9.0(8.4-9.6)$ & $20.0(19.4-20.7)$ & $31.1(30.2-32.0)$ & $25.0(24.2-25.8)$ & $6.6(6.1-7.1)$ & $2.1(1.8-2.3)$ \\
\hline \multicolumn{10}{|l|}{ Grade } \\
\hline 9th & 12,551 & $59.7(58.6-60.8)$ & $5.8(5.2-6.4)$ & $8.4(7.7-9.0)$ & $17.2(16.4-18.0)$ & $28.3(27.3-29.3)$ & $28.5(27.5-29.5)$ & 9.1 (8.4-9.9) & $2.7(2.3-3.2)$ \\
\hline 10th & 12,083 & $67.4(66.1-68.8)$ & $5.9(5.3-6.5)$ & $9.7(8.9-10.6)$ & $20.6(19.6-21.7)$ & $31.2(30.0-32.4)$ & $24.7(23.6-25.8)$ & $5.8(5.2-6.4)$ & $2.1(1.8-2.5)$ \\
\hline 11th & 12,784 & $73.3(72.0-74.5)$ & $6.8(6.1-7.4)$ & $11.9(11.1-12.7)$ & $24.4(23.4-25.4)$ & $30.2(29.2-31.3)$ & $21.0(19.9-22.1)$ & $4.4(4.0-4.9)$ & $1.3(1.1-1.6)$ \\
\hline 12th & 12,952 & $76.6(75.4-77.8)$ & $6.9(6.3-7.5)$ & $12.7(11.9-13.6)$ & $26.3(25.1-27.5)$ & 30.7 (29.6-31.9) & 18.9 (17.9-19.9) & $3.4(3.0-4.0)$ & $1.1(0.8-1.4)$ \\
\hline \multicolumn{10}{|l|}{ Race/Ethnicity } \\
\hline White ${ }^{\S}$ & 22,330 & $68.3(67.3-69.4)$ & $5.1(4.7-5.5)$ & $9.5(8.9-10.1)$ & $21.6(20.8-22.3)$ & $32.2(31.4-33.0)$ & $24.7(23.8-25.5)$ & $5.6(5.2-6.1)$ & $1.3(1.2-1.5)$ \\
\hline Black ${ }^{\S}$ & 9,701 & $71.2(69.9-72.5)$ & $9.2(8.5-10.0)$ & $13.9(12.8-15.2)$ & $23.9(22.9-24.8)$ & $24.2(23.1-25.3)$ & 19.9 (18.9-20.9) & $5.7(5.1-6.3)$ & $3.2(2.8-3.8)$ \\
\hline Hispanic & 13,452 & $67.0(65.5-68.5)$ & $6.7(6.1-7.4)$ & $10.5(9.7-11.4)$ & $20.7(19.8-21.7)$ & $29.1(28.1-30.1)$ & $23.7(22.7-24.9)$ & $6.9(6.3-7.6)$ & $2.3(2.0-2.7)$ \\
\hline $\begin{array}{l}\text { American Indian/ } \\
\text { Alaska Native }^{\S}\end{array}$ & 769 & $60.3(52.4-67.6)$ & $9.8(6.7-14.1)$ & $8.9(6.6-12.0)$ & $18.2(15.1-21.9)$ & $23.3(20.1-26.9)$ & $25.9(21.7-30.7)$ & $8.4(5.4-12.9)$ & $5.4(3.8-7.5)$ \\
\hline Asian $§$ & 1,751 & 75.7 (72.7-78.5) & $8.3(6.4-10.6)$ & $13.2(11.1-15.6)$ & $26.4(23.9-29.1)$ & $27.8(25.2-30.5)$ & $18.1(15.7-20.7)$ & $4.4(3.1-6.3)$ & $1.8(1.1-2.9)$ \\
\hline $\begin{array}{l}\text { Native Hawaiian/ } \\
\text { Pacific Islander }\end{array}$ & 399 & $68.3(62.1-73.9)$ & $12.8(9.0-18.0)$ & $10.8(7.5-15.2)$ & $20.4(16.7-24.7)$ & $24.3(19.3-30.2)$ & $24.2(19.1-30.1)$ & $5.1(3.1-8.5)$ & - \\
\hline Multiracial§ & 1,968 & $72.0(69.2-74.7)$ & $9.2(7.6-11.1)$ & $13.3(11.4-15.5)$ & $22.9(20.4-25.6)$ & $26.6(24.1-29.2)$ & $21.0(18.5-23.6)$ & $4.9(3.8-6.3)$ & $2.1(1.4-3.2)$ \\
\hline
\end{tabular}

Abbreviation: $\mathrm{Cl}=$ confidence interval.

* Weighted percentages.

† Unweighted n's.

$\S$ Non-Hispanic.

ๆ Unreliable estimate. Relative standard error $\geq 0.3$.

of all five injury-related risk behaviors varied by sleep duration (Table 2). The likelihood of each of the five risk behaviors was significantly higher (APR >1.0) among students with sleep durations $\leq 7$ hours; infrequent seatbelt use, riding with drinking driver, and drinking and driving were also more likely among students reporting sleeping $\geq 10$ hours compared with 9 hours (Table 3). The likelihood of drinking and driving was also significantly higher among students sleeping 8 hours compared with 9 hours.

\section{Discussion}

Unintentional injuries are the leading cause of death for adolescents, with approximately two thirds of these fatalities related to road traffic crashes (5). Excessive sleepiness, which is most often a result of not getting adequate sleep, has been shown to increase the risk for motor vehicle crashes and other unintentional injury among adolescents (1-3). Although insufficient sleep contributes to injury risk directly by slowing reaction time, impairing ability to pay attention, or causing a driver to fall asleep $(\sigma)$, this study provides evidence that some of the increased risk associated with insufficient sleep might be caused by engaging in injury-related risk behaviors.
In addition to a higher likelihood of engaging in injury-related risk behaviors among students who reported typically sleeping $\leq 7$ hours on school nights, infrequent seatbelt use, riding with a drinking driver, and drinking and driving were also more likely for students sleeping $\geq 10$ hours compared with 9 hours. Although short and long sleep might simply be associated with other adolescent risk behaviors, insufficient sleep might cause persons to take more risks and disregard the possibility of negative consequences ( 7 ). However, depression might contribute to both sleep problems and participation in risk behaviors. Sleep problems, including both not sleeping enough and sleeping too much, are common symptoms of depression; one study found that adolescents who reported more depressive symptoms were more likely to engage in several injury-related risk behaviors, including infrequent seatbelt use, infrequent bicycle helmet use, and drinking and driving (8).

The findings in this report are subject to at least two limitations. First, the data were self-reported and the extent of any underreporting or overreporting cannot be determined. However, the survey questions demonstrate good test-retest reliability. ${ }^{\dagger \dagger}$ Second, the survey is not representative of school-aged youths

\footnotetext{
$\overline{\dagger \dagger}$ http://www.ncbi.nlm.nih.gov/pubmed/12359379.
} 
Morbidity and Mortality Weekly Report

TABLE 2. Prevalences and $95 \%$ confidence intervals (Cls) of unintentional injury risk behaviors among high school students, by sleep duration - Youth Risk Behavior Surveys, United States, 2007, 2009, 2011, and 2013

\begin{tabular}{|c|c|c|c|c|c|c|c|}
\hline \multirow[b]{2}{*}{ Risk behavior } & \multicolumn{7}{|c|}{ Sleep duration $\%(95 \% \mathrm{Cl})$} \\
\hline & $\leq 4 \mathrm{hrs}$ & $5 \mathrm{hrs}$ & $6 \mathrm{hrs}$ & $7 \mathrm{hrs}$ & $8 \mathrm{hrs}$ & $9 \mathrm{hrs}$ & $\geq 10 \mathrm{hrs}$ \\
\hline Infrequent bicycle helmet use & $91.2(89.2-92.9)^{*}$ & $90.6(88.8-92.2)^{*}$ & $87.9(86.3-89.4)^{*}$ & $85.7(83.9-87.5)^{*}$ & $83.4(81.2-85.4)$ & $81.7(79.2-84.0)$ & $82.5(78.0-86.2)$ \\
\hline Infrequent seatbelt use & $22.8(20.6-25.2)^{*}$ & $12.5(11.2-14.1)^{*}$ & $9.3(8.3-10.5)^{*}$ & $6.5(5.6-7.4)$ & $5.9(5.1-6.8)$ & $5.5(4.5-6.6)$ & $13.1(10.6-16.0)^{*}$ \\
\hline Rode with a drinking driver & $36.8(34.7-39.0)^{*}$ & $31.5(29.8-33.3)^{*}$ & $28.2(26.9-29.4)^{*}$ & $25.1(23.8-26.3)^{*}$ & $21.4(20.2-22.7)$ & $19.8(17.9-21.8)$ & $24.0(20.5-27.9)^{*}$ \\
\hline Drinking and driving & $16.6(14.9-18.4)^{*}$ & $11.2(10.0-12.5)^{*}$ & $10.1(9.2-11.1)^{*}$ & $8.3(7.5-9.2)^{*}$ & $6.7(6.1-7.4)^{*}$ & $4.7(3.9-5.7)$ & $9.9(7.5-12.9)^{*}$ \\
\hline Texting while driving & $32.7(29.3-36.3)^{*}$ & $34.8(31.6-38.1)^{*}$ & $33.4(31.2-35.7)^{*}$ & $31.5(28.7-34.5)^{*}$ & $26.1(23.9-28.4)^{*}$ & $20.9(17.7-24.4)$ & $24.8(20.5-29.7)$ \\
\hline
\end{tabular}

* Prevalence significantly different from 9 hours $(p<0.05)$.

TABLE 3. Adjusted prevalence ratios (APRs)* and $95 \%$ confidence intervals (Cls) for unintentional injury risk behaviors among high school students, by sleep duration — Youth Risk Behavior Surveys, United States, 2007, 2009, 2011, and 2013

\begin{tabular}{|c|c|c|c|c|c|c|c|}
\hline \multirow[b]{2}{*}{ Risk behavior } & \multicolumn{7}{|c|}{ Sleep duration APR $(95 \% \mathrm{Cl})$} \\
\hline & $\leq 4 \mathrm{hrs}$ & $5 \mathrm{hrs}$ & $6 \mathrm{hrs}$ & $7 \mathrm{hrs}$ & $8 \mathrm{hrs}$ & $9 \mathrm{hrs}$ & $\geq 10 \mathrm{hrs}$ \\
\hline Infrequent bicycle helmet use & $1.12(1.08-1.15)$ & $1.11(1.07-1.15)$ & $1.08(1.05-1.11)$ & $1.06(1.02-1.09)$ & $1.02(1.00-1.06)$ & 1.00 (Ref) & $0.99(0.94-1.05)$ \\
\hline Infrequent seatbelt use & $4.50(3.66-5.54)$ & $2.60(2.10-3.22)$ & $1.92(1.60-2.31)$ & $1.28(1.06-1.54)$ & $1.13(0.95-1.36)$ & 1.00 (Ref) & $2.38(1.82-3.11)$ \\
\hline Rode with a drinking driver & $1.84(1.64-2.06)$ & $1.58(1.41-1.77)$ & $1.42(1.27-1.58)$ & $1.27(1.15-1.40)$ & $1.09(0.98-1.20)$ & 1.00 (Ref) & $1.20(1.01-1.42)$ \\
\hline Drinking and driving & $3.14(2.52-3.92)$ & $2.10(1.71-2.58)$ & $1.84(1.49-2.27)$ & $1.51(1.27-1.81)$ & $1.32(1.06-1.64)$ & 1.00 (Ref) & $2.19(1.60-3.00)$ \\
\hline Texting while driving & $1.26(1.05-1.51)$ & $1.29(1.11-1.49)$ & $1.22(1.05-1.41)$ & $1.19(1.03-1.37)$ & $1.10(0.95-1.27)$ & 1.00 (Ref) & $1.24(1.00-1.55)$ \\
\hline
\end{tabular}

* Adjusted for sex, grade, and race/ethnicity.

who do not attend school. Nationwide, in 2012, approximately $3 \%$ of persons aged $16-17$ years were not enrolled in a high school program and had not completed high school.\$\$

The National Sleep Foundation recommends that adolescents aged 14-17 years sleep 8-10 hours per night (4). To help ensure that adolescents get adequate sleep, they can practice good sleep hygiene (i.e., habits that promote good sleep). These habits include going to bed and getting up at the same time each day both during the school week and weekends, minimizing light exposure in the evenings, and keeping computers and other electronic devices, such as computers, video games, and cell phones, out of the bedroom. 99 Parents can help by setting bedtimes and limiting when (only before a set time or "media curfew") and where (not in their bedrooms) their teenagers can use electronic devices. Early school start times contribute to insufficient sleep among adolescents. Delaying school start times has been proposed as a means of allowing adolescents to get adequate sleep (9). Some students naturally need more sleep than their peers, but waking up and feeling unrested in spite of adequate sleep might be an indication of a problem such as poor sleep quality or an underlying health condition. Poor sleep quality might result from poor sleep hygiene, a bad sleep environment (e.g., too warm, too noisy, or cell phones in the bedroom), or a sleep disorder. In addition, long sleep durations might be a symptom of depression.

\footnotetext{
$\$ \$$ http://nces.ed.gov/pubs2015/2015015.pdf.

99 More tips for good sleep are available from the National Sleep Foundation

(https://sleepfoundation.org/sleep-tools-tips/healthy-sleep-tips).
}

Various resources are available to address injury-related risk behaviors. Public health practitioners can refer to systematic reviews of interventions included in The Community Guide (http://www.thecommunityguide.org/mvoi/index. html). Some evidence exists that health care providers, in collaboration with health educators, might be able to change adolescent injury-related behavior through screening and brief counseling, followed by a visit by a health educator $(9,10)$. Information for parents of teen drivers on what they can do to encourage safe driving by their teens is available at http://www.cdc.gov/parentsarethekey/parents/index.html.

\section{Summary}

What is already known about this topic?

Insufficient sleep is common among high school students and is associated with an increased risk for unintentional injury from drowsy driving crashes and other causes.

What is added by this report?

Students who reported sleeping $\leq 7$ hours on school nights were more likely to report several injury-related risk behaviors (infrequent bicycle helmet use, infrequent seatbelt use, riding with a driver who had been drinking, drinking and driving, and texting while driving) compared with students who sleep 9 hours. What are the implications for public health practice?

High school faculty and administrators, as well as parents of high school students, should be made aware of the increased likelihood for risky behavioral choices among students who do not get enough sleep. 


\section{Acknowledgment}

Ruth A. Shults, Division of Unintentional Injury Prevention, National Center for Injury Prevention and Control, CDC.

${ }^{1}$ Division of Population Health, National Center for Chronic Disease Prevention and Health Promotion, CDC; ${ }^{2}$ Division of Adolescent and School Health, National Center for HIV/AIDS, Viral Hepatitis, STD, and TB Prevention, CDC.

Corresponding author: Anne G. Wheaton, awheaton@cdc.gov, 770-488-5362.

\section{References}

1. Martiniuk AL, Senserrick T, Lo S, et al. Sleep-deprived young drivers and the risk for crash: the DRIVE prospective cohort study. JAMA Pediatr 2013;167:647-55. http://dx.doi.org/10.1001/jamapediatrics.2013.1429

2. Milewski MD, Skaggs DL, Bishop GA, et al. Chronic lack of sleep is associated with increased sports injuries in adolescent athletes. J Pediatr Orthop 2014;34:129-33. http://dx.doi.org/10.1097/ BPO.0000000000000151

3. Graves JM, Miller ME. Reduced sleep duration and history of work-related injuries among Washington state adolescents with a history of working. Am J Ind Med 2015;58:464-71. http://dx.doi.org/10.1002/ajim.22416
4. Hirshkowitz M, Whiton K, Albert SM, et al. National Sleep Foundation's sleep time duration recommendations: methodology and results summary. Sleep Health 2015;1:40-3. http://dx.doi.org/10.1016/j.sleh.2014.12.010

5. CDC. Vital signs: unintentional injury deaths among persons aged 0-19 years-United States, 2000-2009. MMWR Morb Mortal Wkly Rep 2012;61:270-6.

6. Williamson A, Lombardi DA, Folkard S, Stutts J, Courtney TK, Connor JL. The link between fatigue and safety. Accid Anal Prev 2011;43:498515. http://dx.doi.org/10.1016/j.aap.2009.11.011

7. Harrison Y, Horne JA. The impact of sleep deprivation on decision making: a review. J Exp Psychol Appl 2000;6:236-49. http://dx.doi. org/10.1037/1076-898X.6.3.236

8. Testa CR, Steinberg L. Depressive symptoms and health-related risktaking in adolescence. Suicide Life Threat Behav 2010;40:298-305.

9. Adolescent Sleep Working Group, Committee on Adolescence, Council on School Health. School start times for adolescents. Pediatrics 2014;134:642-9. http://dx.doi.org/10.1542/peds.2014-1697

10. Ozer EM, Adams SH, Orrell-Valente JK, et al. Does delivering preventive services in primary care reduce adolescent risky behavior? J Adolesc Health 2011;49:476-82. http://dx.doi.org/10.1016/j.jadohealth.2011.02.011 